\title{
Pedagogia freireana na comunicação: diversidade e saúde
}

\author{
Merli Leal Silva', Dora Djanira Bragança Castagnino²
}

\begin{abstract}
Resumo
Este trabalho descreve e analisa os processos de construção de campanha publicitária criada coletivamente por movimentos sociais, universidade e agência de propaganda, integrando saúde, gênero e comunicação. O foco é a saúde de mulheres, no contexto de uma campanha a ser veiculada em meios alternativos pelo movimento social Liga Brasileira de Lésbicas (LBL). Este trabalho problematiza a questão, apontando dados e pesquisas realizadas sobre saúde feminina, e apresenta o percurso metodológico freireano possível para a criação de materiais de comunicação para públicos específicos. A base bibliográfica referencial é o método de educação popular de Paulo Freire e os Estudos Culturais de Raymond Willians, autores fundamentais para a descrição do método freireano para a criação de campanhas de publicidade em saúde.
\end{abstract}

\section{Palavras-chave}

Publicidade. Saúde. Gênero. Pedagogia Freireana. Diversidade Sexual.

1. Doutora em Educação pela Universidade de São Paulo, com estágio doutoral pela Universitat de Valencia (Espanha), professora da Universidade Federal do Pampa, onde coordena o projeto de extensão "Pedagogia Freireana: Educação Social no Campo". E-mail: merlileal@gmail.com.

2. Graduada em Comunicação Social, Publicidade e Propaganda pela Associação Escola Superior de Propaganda e Marketing de Porto Alegre, onde coordena a Agência Experimental Social e atua como professora da Escola de Criação ESPM. E-mail: patuaresponsavel@gmail.com. 


\title{
Freirian pedagogy in communication: gender and health
}

\author{
Merli Leal Silva*, Dora Djanira Bragança Castagnino**
}

\begin{abstract}
This work describes and analyses the construction process of advertising campaigns that are created collectively between social movements, university, and publicity agencies, integrating health, gender, and communication. The focus is the women health, in the context of a campaign that will be conveyed in alternatives medias created by the social movement Liga Brasileira de Lésbicas (LBL). This work will problematize the question, will point data and researches realized about feminine health, moreover will present the possible freirian method for the creation of communication materials for specific publics. The referential bibliography will be the Paulo Freire's popular education method, the Raymond Willians' Cultural Studies. These authors will be crucial to describe the freirian method and to the health advertising creation campaigns.
\end{abstract}

\section{Keywords}

Advertising. Gender Health. Freire's Pedagogy. Sexual Diversity.

\footnotetext{
* Doctor in Education at the University of São Paulo, with internship at the Universitat de Valencia (Spain), professor at the Federal University of Pampa, where coordinates the extension project "Pedagogia Freireana: Educação Social no Campo". E-mail: merlileal@gmail.com.

* Graduated in Social Communication, Publicity and Advertising at Associação Escola Superior de Propaganda e Marketing de Porto Alegre, where coordinates the Agência Experimental Social and works as professor at Escola de Criação ESPM. E-mail: patuaresponsavel@gmail.com.
} 


\section{Introdução}

Os movimentos sociais são fundamentais para a busca de ampliação dos direitos dos cidadãos. O Estado, quando pressionado pelos movimentos, esforça-semais parabuscarsoluções para problemas que afligem o povo, além de absorver as reivindicações dos movimentos e, de certa forma, os esvaziar de sentido.

Desta forma, a luta dos movimentos sociais ligados às questões de homofobia e homossexualidade é crucial para os avanços conquistados no ano de 2013, com a legalização do casamento igualitário. Ainda assim, as especificidades de lésbicas e bissexuais são ignoradas pelo sistema de saúde público ou privado.

O fato de as lésbicas não revelarem aos médicos suas prática sexuais, possivelmente por medo, vergonha ou falta de acolhimento, tem se mostrado um problema recorrente. Parece faltar o "clima" para uma escuta, além de profissional e ética, acolhedora e sensível. A pergunta clássica do ginecologista parece ser sempre "Qual método contraceptivo você usa?". E isso sem perceber que, antes desse questionamento, há de se compreender qual o tipo de prática sexual a paciente mantém. Enfim, esse desencontro com a cultura lésbica leva a muitas mortes. Muitas mulheres não fazem exames preventivos, o que só tende a piorar sua situação.

O atendimento realizado pelo profissional de saúde ignora a diversidade e o aspecto holístico do que significa ser mulher. Os meios de comunicação veiculam um padrão de mulher: branca, jovem e heterossexual. A possibilidade de diversidade em um país continental como o Brasil é gigante e, infelizmente, muito mal representada. A LBL-RS 3 tem lutado muito no campo da saúde das mulheres. Contudo, é necessário pensar em estratégias no campo da educação e da comunicação, a fim de mostrar outras imagens e textos que possam visibilizar milhares de mulheres. Há, no Brasil, uma ausência de comunicação focada para o público lésbico. Daniela Knauth (2009, p. 12), relata o abismo entre o sistema de saúde e as lésbicas e bissexuais:

Os dados sobre as mulheres indicam que a
saúde em geral é um tema delicado, porque
envolve experiências de discriminação e
expectativas de desconforto, particularmente
em relação à consulta ginecológica. As
mulheres masculinas tendem a evitar os
médicos, acionando os serviços de saúde, em
geral, apenas nas situações que se percebem
incapacitadas para o trabalho ou atividades
cotidianas. A abordagem das questões
de prevenção faz pouco sentido para as
entrevistadas, porque elas não percebem
riscos nas suas práticas sexuais e o tema
desperta tensões no que diz respeito ao
imperativo da fidelidade conjugal e a própria
afirmação de uma identidade lésbica.

O relato das mulheres pesquisadas surpreende por mostrar a inabilidade de todo um sistema público de saúde no acolhimento à diversidade. A invisibilidade lésbica alicerça-se nas relações de poder entre os gêneros. Os gays masculinos são discriminados, mas são visíveis. Na visibilidade, a luta e o enfrentamento são constantes e a orientação sexual é nítida, não ocultada.

3. A Liga Brasileira de Lésbicas é uma expressão do movimento social, de âmbito nacional, que se constitui como espaço autônomo e não institucional de articulação política, anticapitalista, antirracista, não lesbofóbica e não homofóbica, e de articulação temática de mulheres lésbicas e bissexuais, pela garantia efetiva e cotidiana da livre orientação e expressão afetivo-sexual. É um movimento que se soma a todos os movimentos sociais que lutam e acreditam que outro mundo é possível. A LBL é uma articulação de grupos, entidades, movimentos, lésbicas e bissexuais autônomas/independentes que dela participam. Acesse o blog da LBL NACIONAL: <http:// Iblnacional.wordpress.com/>. 
Temos, pois, que o sistema de saúde não enxerga, a comunicação não divulga e a sociedade ignora. Segundo Raymond Williams (2011), leis, constituições, teorias e ideologias defendidas como naturais e universais são, na verdade, a expressão e a ratificação da dominação de uma classe particular. O que prevalece, dentro da cultura hegemônica, é a invisibilidade do que foge à normatividade. Neste sentido, há um concerto de aparelhos ideológicos do Estado para invisibilizar grupos não hegemônicos na sociedade: escola, igreja, família e meios de comunicação, discursivamente, ignoram a orientação lésbica.

Nesta perspectiva, a metodologia freireana e os estudos culturais são referências fundamentais para se entender os processos de exclusão de determinadas classes do contexto social mais amplo. Paulo Freire e outros (1981) creem na luta política pela busca de uma consciência crítica que faça com que os excluídos adquirem visibilidade e usufruam dos direitos que têm na sociedade, que, ao fim e ao cabo, é de todos. Toda teoria freireana parte do pressuposto de que não é possível ensinar sem aprender, de que nada pode ser naturalizado e de que a subjetividade pode fazer as pessoas mudarem a realidade. Nada está posto ou dado, é na luta por uma cultura de acolhimento ao diverso que as mulheres sempre se mobilizaram dentro do movimento lésbico feminista. Como movimento social, as organizações de luta lésbica não são homogêneas. Há diferentes correntes ideológicas e formas de lidar com o acesso aos direitos em processo de consolidação da cidadania lésbica. A hegemonia ainda é o comportamento heteronormativo.

Williams (2011) ratifica o conceito de hegemonia de Gramsci, autor também referenciado por Paulo Freire em toda a sua obra:

Os modos de incorporação são de grande importância social. As instituições educacionais são geralmente as principais agências de transmissão de uma cultura dominante eficaz, e essa é agora uma atividade tanto econômica quanto cultural prioritária; na verdade, são ambas ao mesmo tempo [...]. (WILLIAMS, 2011, p. 54).

A transmissão de um padrão para a sexualidade das pessoas por meio dos currículos escolares constrói, discursivamente, a política das relações de gênero na sociedade. Subverter a ordem significa opor-se ao sistema e propor novas formas relacionais não estabelecidas.

O que fica nítido é que não é possível aceitar, sem luta, a invisibilidade no Sistema Único de Saúde (SUS). Na pesquisa referida de Knauth (2009), foram ouvidos profissionais da saúde, para se entender o motivo de negligenciarem as práticas sexuais de suas pacientes/usuárias no atendimento.

Em síntese, pode-se afirmar que todos os entrevistados consideram a formação em medicina como "insuficiente" e "pouco científica" para abordar as temáticas relacionadas à sexualidade. No depoimento da ginecologista, que trabalha no serviço especializado em HIV, pode-se evidenciar essa percepção: "A gente tem na UFRGS, na cadeira de Ginecologia mesmo, tem alguma uma coisa muito superficial. Na verdade, assim, sobre a sexualidade, tem professor que faz essa, essa especialidade ali no [Hospital de] Clínicas, na residência, algum contato. Mas tenho que dizer que é ruim, que não é não é uma coisa muito científica assim. [...] A gente teve algumas aulas sobre orgasmo, platô e não sei o quê, mas uma aulinha disso e o restante tudo papagaiada assim, nada muito que nos ajudasse muito, a longo prazo, a gente tem muita dificuldade". (KNAUTH, 2009, p. 29)

O sistema educativo considera apenas os valores da classe dominante na construção dos currículos e temas de ensino. Nos meios de comunicação, as relações sociais de gênero se constituem a partir do casal homem e mulher. Cremos que a finalidade da ação comunicativo-educativa deve 
ser a inclusão de novos conhecimentos. Em comunicação popular, os processos geralmente ocorrem de forma horizontal, dialógica, emancipatória e politizada. Neste sentido, emissor e receptor se mesclam, trocando de lugar no processo da busca da mensagem que realmente tem significado político e libertador. O ponto de partida é a experiência e a percepção dos grupos específicos, sua leitura de mundo e de realidade. Um novo saber/fazer emerge, integrando comunicação e educação, em uma perspectiva inclusiva e positiva. As contradições dentro do movimento popular contribuem para construir um olhar diverso, amplo e não excludente. É no debate e no dissenso que as conquistas acontecem.

Williams (2011) identifica, na sociedade, as práticas alternativas e as práticas opositoras. Para o autor, o alternativo pode ser incorporado ao sistema dominante como sendo exótico e, assim, tolerado. Já as práticas opositoras devem ser vencidas e eliminadas do contexto social. A maneira de operacionalizar essa eliminação é por meio da invisibilização da prática opositora. O opositor quer mudar o que está posto. Ele tem um comportamento diferente do padrão e serve de referência para outros grupos sociais. É uma forma de funcionamento bastante nefasto, uma vez que mata socialmente um grupo humano.

Sem existência legal ou reconhecimento social, as pessoas são pela metade, ou nem são. As mulheres do movimento gay, no Brasil, possuem representação junto a vários órgãos nacionais e internacionais de saúde lésbica e lutam por diversas pautas fundamentais para a sua cidadania.

Há uma distinção teórica simples entre o alternativo e o opositor, isto é, entre alguém que meramente encontra um jeito diferente de viver e quer ser deixado só, e alguém que encontra uma maneira diferente de viver e quer mudar a sociedade. Essa é geralmente a diferença entre soluções individuais e de pequenos grupos para a crise social, e as soluções que pertencem a prática política e, sobretudo, revolucionária. (WILLIAMS, 2011, p. 58).

\section{Comunicação como espaço de educação e visibilidade}

Comunicar pode ser a forma de educar para um mundo verdadeiramente mais inclusivo. As imagens e os textos sedutores dos meios de comunicação veiculam ideologias que, em alguma medida, podem influenciar nossa forma de ver o mundo. Eles tentam criar uma representação da realidade a partir de uma leitura particular do mundo, ligada a vários interesses do capital. Ancorando a imagem, o texto provoca e induz uma ação concreta por parte de emissores e receptores, seja positiva, negativa ou indiferente.

A luta da propaganda como produtora de sentidos é não passar despercebida. Significar é fundamental para operacionalizar a ideologia hegemônica. O pensamento de Paulo Freire, como referência metodológica, faz toda a diferença como processo e resultado. Ampliando a participação do povo para a mobilização e a conscientização política, o método freireano busca levantar conteúdos coletivos que representem a angústia dos grupos excluídos. Ao debater sua realidade, problematizando-a, o grupo oprimido luta pela inclusão de seus valores e significados na sociedade.

Para Freire (1980), utopia não é algo irrealizável ou um mero idealismo. Na verdade, é um compromisso histórico, denunciador da estrutura desumanizante e anunciador de possibilidades humanizadoras. Para o autor, devemos nos comprometer radicalmente com a transformação do mundo, a fim de que todos possam "ser mais". As pessoas reacionárias e opressoras não podem ser utópicas e nem ter esperança. Quanto mais conscientizados estamos, mais comprometidos com a mudança somos; é um compromisso permanente de 
transformação social, rumo a uma sociedade mais plural e diversa. Ao fim e ao cabo, Freire nos faz refletir sobre nosso papel no mundo: "a transformação permanente da realidade para a libertação dos homens" (FREIRE, 1980, p. 29). Mas, afinal, qual o papel da comunicação popular em saúde? Criar possibilidades alternativas de comunicação sobre a realidade do sistema de saúde e o sentimento das usuárias, dando-lhes voz e imagem nos meios de comunicação. Contudo, é fundamental pensar em possibilidades novas de imagem e texto sobre as mulheres lésbicas e bissexuais no contexto social. Neste sentido, a opção por criar uma campanha publicitária para os diferentes públicos surgiu da própria ausência na propaganda da mídia hegemônica. Com um discurso construído em dialogia com os movimentos sociais, a ideia foi propor a mudança comportamental na sociedade, a partir de uma reflexão crítica. Chamar atenção, induzir à ação, fazer perceber a mensagem e não esquecê-la, eis alguns pressupostos da propaganda enquanto técnica comunicativa.

Contudo, ao pensar em campanhas de saúde pública, por vezes o público não é atingido por não se identificar com as mensagens veiculadas, geralmente produzidas por profissionais que não interagem com os públicos específicos. Quantos anúncios são veiculados nas mídias sobre famílias gays? Quantas novelas mostram relações lésbicas em suas tramas? Como as campanhas de saúde pública tratam o tema? Um educocomunicador popular no campo da saúde tem o papel de salvar vidas pelo uso adequado de mensagens nos meios de comunicação. Ele vai buscar nas raízes do contexto cultural dos grupos sociais a linguagem adequada, a inflexão correta, a emoção e o riso, o contexto fundando o texto. A pesquisa de campo com os grupos, buscando conhecer sua realidade e demandas cotidianas, alicerça discurso e prática comunicativa eficientes e focados, com reais condições de promover mudanças na sociedade como um todo. No caso da saúde das mulheres lésbicas, o relatório da pesquisa citada mostra alguns caminhos possíveis para debelar o preconceito presente no SUS e entre as próprias lésbicas em risco. Segundo Knauth (2009, p. 63),

[...] estes achados sugerem que as políticas de saúde devem investir, por um lado, na capacitação dos médicos, habilitando estes profissionais a tratarem as especificidades de saúde e sexualidade da população de mulheres que fazem sexo com mulheres. Por outro, deve-se promover campanhas direcionadas às próprias mulheres que fazem sexo com mulheres no sentido de incentiválas a buscar um acompanhamento médico preventivo e regular, familiarizá-las com o uso do preservativo visando evitar uma gravidez não planejada e doenças sexualmente transmissíveis [...].

A pesquisadora crê que uma campanha publicitária voltada aos médicos, mulheres lésbicas e bissexuais, assim como para a população em geral, pode trazer importantes mudanças comportamentais a médio e longo prazo. A construção de uma sociedade não homofóbica passa pela reformulação dos estereótipos grotescos, efeminados, desumanizadas e pervertidos veiculados nos meios de comunicação. Enfim, o sistema de saúde integra um sistema maior e precisa começar a fazer a sua parte, acolhendo integramente a diversidade. Cabe citar Simone de Beauvoir (1980, p. 164):

Na realidade, a homossexualidade não é nem uma perversão deliberada nem uma maldição fatal. É uma atitude escolhida em situação, isto é, a um tempo motivada e livremente adotada. É para a mulher uma maneira, entre outras, de resolver os problemas postos por sua condição em geral, por sua situação erótica em particular. Como todas as condutas humanas, ela acarretará comédias, desequilíbrio, malogro, mentira ou, ao contrário, será fonte de experiências 
fecundas, segundo seja vivida na má-fé, na preguiça, na inautencidade ou na lucidez, na generosidade e na liberdade [...].

\section{A saúde das mulheres lésbicas e bissexuais como tema gerador}

Mulheres lésbicas e bissexuais sentem-se inibidas em procurar ajuda médica no sistema de saúde público. Revelar a intimidade em um contexto social de enorme preconceito não é tarefa fácil. Ainda existe o medo de se ver submetida ao uso de instrumentos médicos invasivos (como o espéculo), especialmente quando se trata daquelas que não sofrem penetração em suas relações sexuais.

Embora não seja possível estimar quantas usam o sistema, pois não existe a possibilidade de informação da orientação sexual no prontuário médico, apontamos para a falta de um espaço adequado para diálogo sobre as dúvidas e práticas sexuais desse grupo. A falta de acolhimento por parte do corpo de profissionais de saúde na rede pública, somadas ao medo da rejeição e ao preconceito efetivamente existentes, faz com que muitas mulheres saiam dos consultórios com recomendações para usar pílulas anticoncepcionais ou camisinhas masculinas nas relações. Ao não visibilizar essas mulheres, o sistema cria uma barreira na detecção e prevenção de doenças de toda ordem. Qual o papel da comunicação para a mudança deste cenário? Possivelmente, considerar a mulher em sua integralidade e diversidade na hora de construir uma estratégia comunicativa.

\section{A práxis freireana: ação, reflexão, ação}

O percurso para construir com os grupos estratégias de comunicação pode ser visto por publicitários tradicionais como perda de tempo. O ideal é utilizar o briefing4, pesquisas, dados do consumidor e formar um comitê de especialistas criativos para elaborar as propostas. Posteriormente, aprova-se com quem tem o poder de decidir qual a mensagem mais adequada, e o projeto é veiculado. Com os movimentos sociais, a formação política é a base de qualquer decisão, inclusive das decisões de comunicação. $\mathrm{O}$ investimento feito em dinâmicas de produção coletiva demanda tempo, escuta sensível, humildade e abertura para aprender e ensinar.

Contudo, como o tempo é pouco para uma acumulação de conhecimentos sobre os mais diversos temas e matérias, define-se como objetivo prioritário a aquisição de um método de trabalho a partir do estudo em profundidade de um tema em particular, método este que, em seguida, pode ser aplicado a qualquer tema [...]. (FREIRE et al., 1981, p. 23).

A educação popular freireana busca superar os saberes fragmentados e parciais, quase sempre resultantes de experiências sociais do grupo com exclusão, invisibilidade e opressão. Como processo educativo, produzir conteúdos comunicativos para demandas específicas significa debater a realidade e a necessidade de transformá-la a partir de discursos não hegemônicos.

Produzir conteúdos que eduquem e pautem a mudança nas relações sociais pressupõem basicamente: alcançar uma compreensão dos mecanismos de base que explicam o funcionamento da realidade social; favorecer uma aquisição de conhecimentos úteis ao processo de transformação dessa realidade; permitir um trabalho ao nível das estruturas de pensamento e de linguagem, com ênfase particular na produção de mensagens

4. O briefing publicitário tem como significado a transferência de informações dos anunciantes para com os profissionais da agência. Portanto, é imprescindível a seleção de informações relevantes para as pessoas que as receberão. 
que possam provocar rupturas no senso-comum sobre lesbianidade.

Cabe ressaltar que, a partir de uma perspectiva dos estudos culturais, segundo Escosteguy (2006, p. 146),

[...] os meios de comunicação de massa não são simples instrumentos de manipulação e controle, mas sim produtos culturais como agentes de reprodução social, complexos, dinâmicos e ativos na construção da hegemonia [...].

Para a autora, nosso foco é estudar as estruturas e processos por meio dos quais a comunicação de massa sustenta e reproduz a estabilidade social e cultural. Temos de negociar sentidos o tempo todo, pois há uma correlação de forças sociais que definem o sentido válido para a maioria da sociedade.

Um grupo que não expressa concretamente temas geradores sugere algo trágico: os temas do silêncio e da invisibilidade. Esses assuntos sugerem, na visão freireana, uma estrutura de mutismo frente à força esmagadora das situações-limite. Para Freire, problematizar os temas que nos afastam de sermos mais sãos é base do processo lento de conscientização:

Procurar um tema gerador é procurar o pensamento do homem sobre a realidade e a sua ação sobre esta realidade que está em sua práxis. Na medida em que os homens tomam uma atitude ativa na exploração de suas temáticas, nessa medida sua consciência crítica da realidade se aprofunda e anuncia estas temáticas de realidade. (FREIRE, 1980, p. 32).

\section{A pesquisa como fonte criativa}

O processo de construção da campanha publicitária deu-se a partir dos dados da pesquisa realizada na UFRGS, citada anteriormente. A
LBL-RS e a equipe de criação da Agência Patuá produziram um projeto coletivo, desde a criação dos textos e seleção das imagens. A consultoria técnica ficou por conta do NUPACS-UFRGS.

A missão da pesquisa" "Mulheres que fazem sexo com mulheres e acesso à saúde". Os objetivos da pesquisa delimitaram o foco da comunicação: investigar a influência da sexualidade no acesso das mulheres que fazem sexo com mulheres ao Serviço Público de Saúde; abordar os fatores transversais de vulnerabilidade às DSTs e AIDS de um grupo que, geralmente, fica de fora das pesquisas na área de saúde coletiva; aproximar o movimento social organizado da lógica acadêmica de produção de conhecimento; discutir o acesso à saúde como direito humano, promovendo uma reflexão sobre os padrões de gênero que orientam o atendimento de saúde.

Foram realizadas 14 entrevistas em 2009 com médicos que atuam em serviços médicos municipais, seja de atenção primária à saúde (UBS e PSF) e ambulatórios especializados (DST/AIDS). Buscando-se contemplar diferentes formações médicas, privilegiamos a abordagem de clínicos gerais, médicos de família e comunidade, ginecologistas e infectologistas.

Foram ouvidas 35 mulheres de Porto Alegre e região metropolitana daquela capital. O grupo foi constituído por mulheres entre os 30 e os 60 anos, no ano de 2009. A maioria delas (25) vivendo em situação conjugal. Em relação à cor da pele, constatou-se que grande parte (16) era negra ou parda. O nível de discriminação aparece no trecho da entrevista feita pela pesquisa do NUPACS (Núcleo de Pesquisa em Antropologia do Corpo e da Saúde):

Uma entrevistada conta que foi atendida de porta aberta, por causa do seu jeitão masculino (Paciente). Depois de aguardar na

5. Cf. KNAUTH, D. R. As faces da homofobia no campo da saúde. Disponível em: < http://www.aids.gov.br/ pagina/dados-cientificos-do-projeto-financiado?ident $=280-2007>$. 
fila vendo todas as pessoas sendo examinadas com a porta fechada, a médica mantém a porta aberta para o atendimento e ainda chama um guarda que fica no corredor de espera" (Médica). (NUPACS, 2009, destaques dos autores).

\section{Criação de conteúdo no círculo da cultura}

Após várias reuniões, o conceito da campanha foi criado. A necessidade era falar com lésbicas e profissionais da saúde sobre a especificidadedeatendimentonopostodesaúde.

Os dados da pesquisa ratificam que as mulheres lésbicas são excluídas do sistema por não terem sua identidade sexual reconhecida. Importante ressaltar que elas também são provocadas a dizer algo e a não ocultarem sua condição.

A campanha parte do pressuposto que a saúde não combina com preconceito. $\mathrm{O}$ sistema de saúde deve acolher a todas as mulheres. As imagens foram produzidas em um ponto cultural na cidade de Porto Alegre e todas as mulheres são lésbicas e cederam sua imagem sem custos para a campanha. O grande problema foi conseguir captar a realidade de cada uma nas imagens produzidas, saindo do estereótipo. A comunicação popular é produzida "com" e não "para". Os sujeitos são incluídos no processo de divulgação de sua realidade a partir do seu olhar, negociado com a técnica e estética da propaganda. Baseado na pesquisa do NUPACS, tentamos, em cada peça, explorar as questões apontadas nos resultados. Optamos por criar, ouvindo muito o público-alvo da campanha, por meio em depoimentos e experiências reais. A abordagem textual objetivou atingir àquelas mulheres mais vulneráveis aos problemas de saúde, por meio do uso de uma linguagem dentro do repertório do grupo. O texto é direto, escrito a partir das situações reais relatadas pelas mulheres-foco do projeto. Nas peças para os profissionais de saúde, a abordagem éinformativa e também sensibilizadora para os dados. As figuras 1, 2 e 3 são exemplos de peças publicitárias criadas para a campanha, com foco no público-alvo. O trabalho de criação e produção foi feito de forma coletiva, usando círculos de cultura e muito diálogo sobre o que deveria ser dito. As figuras 1 e 2 têm como foco sensibilizar as mulheres lésbicas que usam os postos de saúde. Já o cartaz (figura 3) foi veiculado dentro dos postos de saúde e teve como alvo toda a comunidade e profissionais da saúde. 
Figura 1 - Cartão postal ${ }^{6}$ para ser distribuído em bares gays.
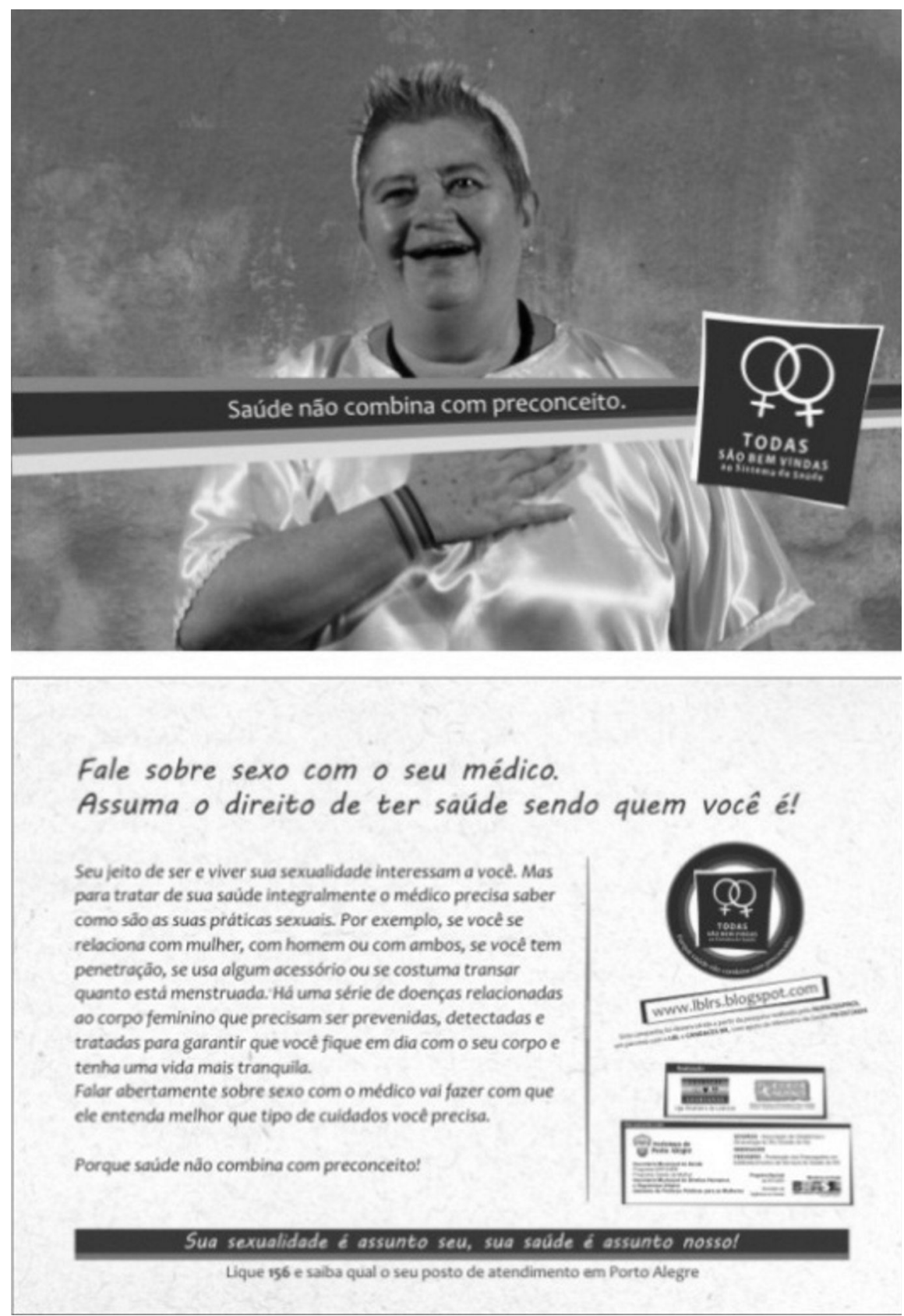

Fonte: Acervo das autoras.

6. Pôster criado pela autora, sob encomenda da Liga Brasileira de Lésbicas e NUPACS-UFRGS. Disponível em: $<$ http://www.Isaudelesbica.blogspot.com.br/>. 
Figura 2 - Cartão postal ${ }^{7}$ para ser distribuído em bares gays.
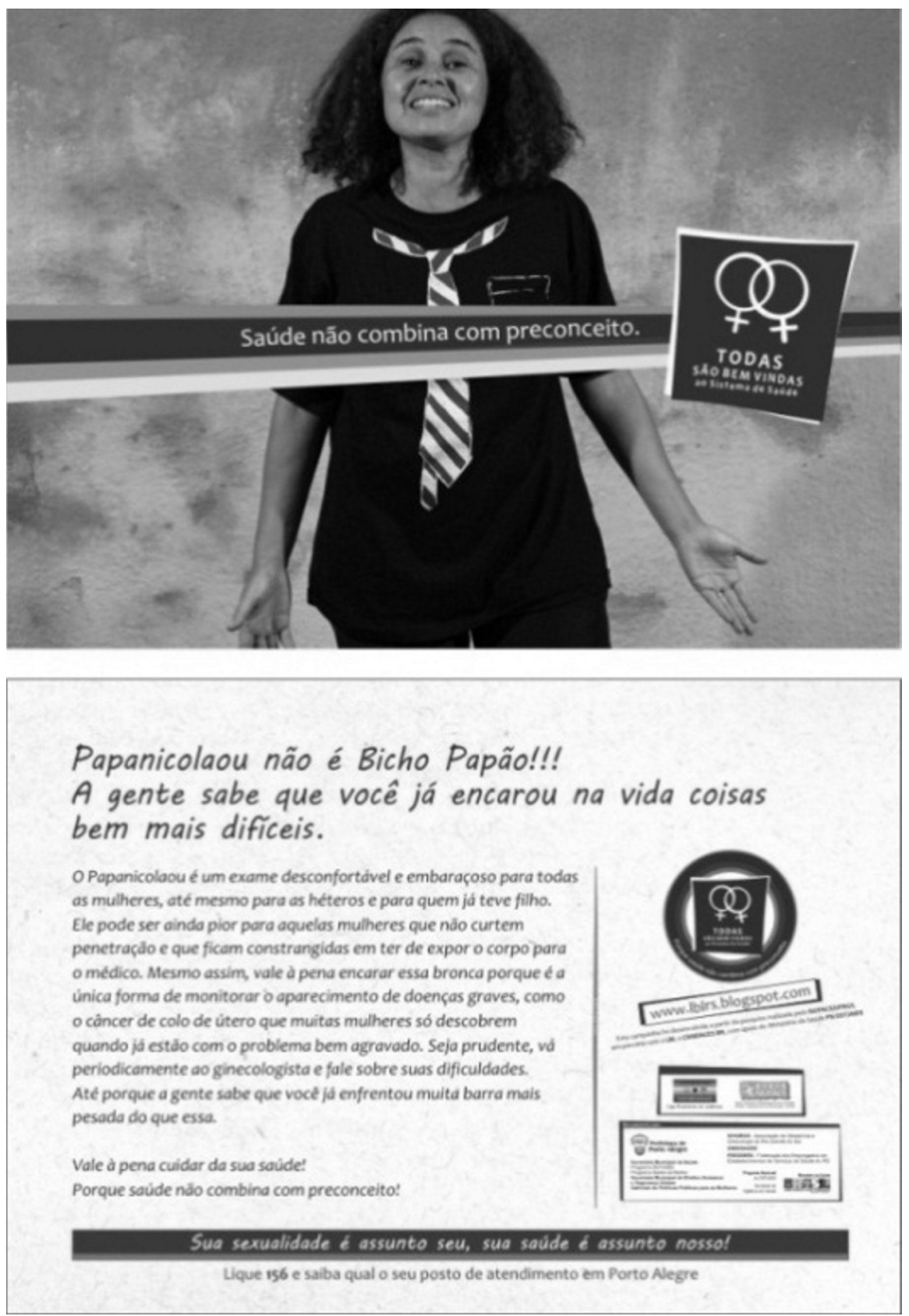

Fonte: Acervo das autoras.

7. Pôster criado pela autora, sob encomenda da Liga Brasileira de Lésbicas e NUPACS-UFRGS. Disponível em: $<$ http://www.Isaudelesbica.blogspot.com.br/>. 
Figura 3 - Cartaz $^{8}$ para os postos de saúde.

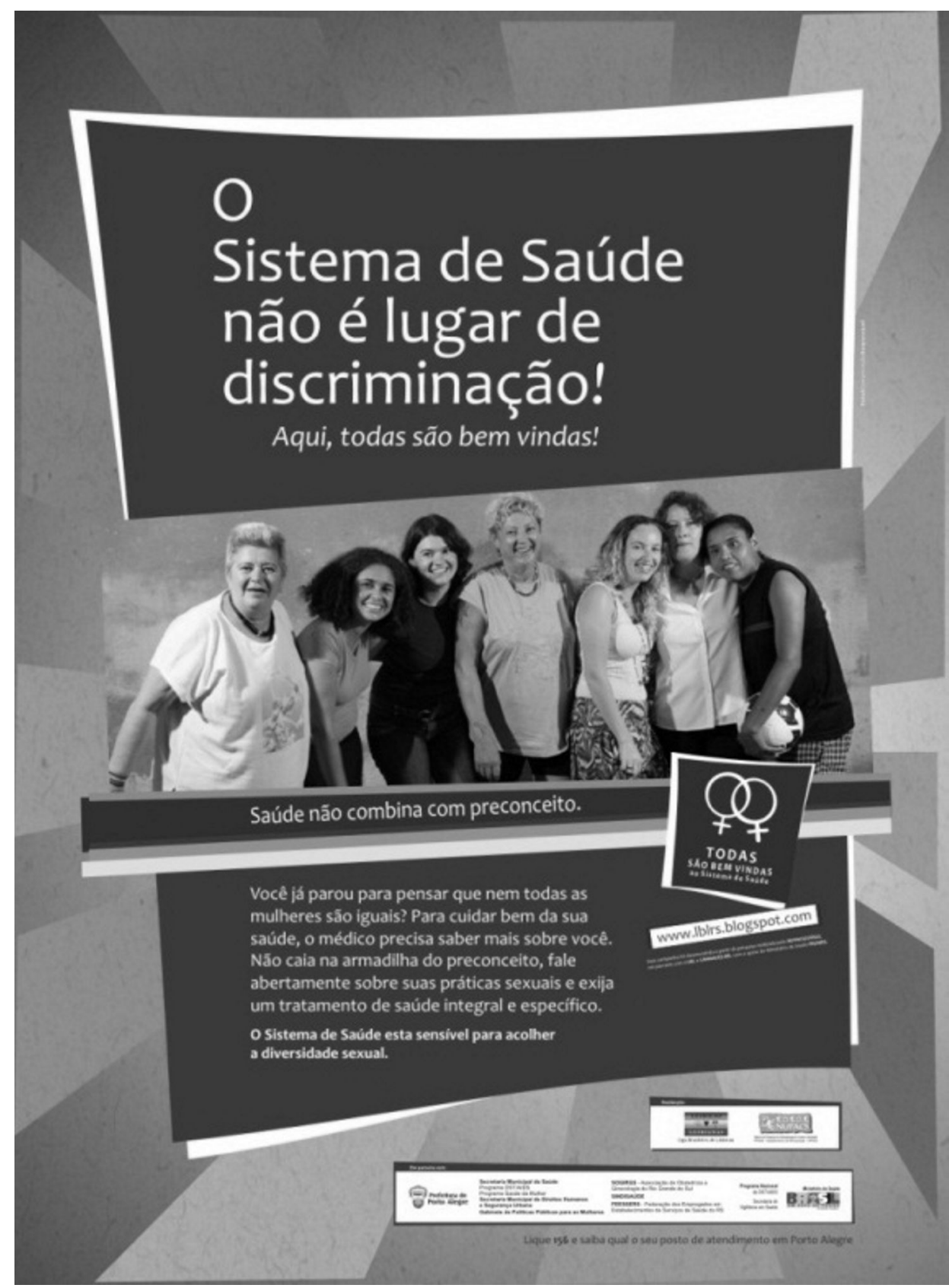

Fonte: Acervo das autoras.

8. Cartaz criado pela autora, sob encomenda da Liga Brasileira de Lésbicas e NUPACS-UFRGS. Disponível em: $<$ http://www.Isaudelesbica.blogspot.com.br/>. 


\section{Considerações Finais}

O trabalho de comunicação popular integrado ao campo da saúde tem urgência e pertinência. Precisamos considerar novos modelos de produção de conteúdo que sejam adequados a uma sociedade cada vez mais conectada e diversificada. Se os públicos ausentes da mídia e das ações de acolhimento do sistema de saúde não têm total acesso a serviços básicos, algo precisa ser revisto.

Manter mulheres lésbicas invisíveis nos protocolos de saúde é negar-lhes cidadania. Ouvir a comunidade lésbica, integrar os conhecimentos dela com a academia e dialogar com os grupos são ações fundamentais para mudar a realidade nefasta que infecta de preconceito o sistema de saúde.

Urge que os movimentos sociais lutem na busca de seus diretos e que os materiais produzidos sejam fruto de um coletivo, criados de forma humanizada e sem padrões e preconceitos; que sejam esteticamente agradáveis e baseados na realidade das comunidades, elaborados em círculos de cultura e vivências coletivas e problematizadoras. Os profissionais de saúde também são público fundamental na interface do acolhimento. A pesquisa mostrou que há um pacto subliminar de silêncio a respeito da homossexualidade: os profissionais não falam sobre este assunto devido ao medo de invasão de privacidade, de discriminação das pacientes ou simplesmente por não se sentirem preparados (tecnicamente) para abordar o assunto. Neste sentido, a comunicação tem o papel de informar e ampliar as possibilidades, a fim de que todos entendam o que precisa ser feito, de forma a eliminar o preconceito, definitivamente, do nosso sistema de saúde.

\section{Referências}

BEAUVOIR, S. de. O segundo sexo. Tradução de Sérgio Milliet. Rio de Janeiro:Nova Fronteira, 1980.

ESCOSTEGUY, A. C. Estudos culturais: uma introdução. In: SILVA, T. T. (Org.) O que é, afinal, estudos culturais? 3. ed. Belo Horizonte: Autêntica, 2006.

FREIRE, P. Conscientização: teoria e prática da libertação, uma introdução ao pensamento de Paulo Freire. São Paulo: Moraes, 1980.

FREIRE, Paulo et al. Vivendo e aprendendo: experiências do IDAC em educação popular. São Paulo: Brasilense, 1981.

KNAUTH, D. R. As faces da homofobia no campo da saúde. Porto Alegre: Fundação Médica do Rio Grande do Sul, 2009. (Relatório Técnico). Disponível em: < http://www.aids.gov.br/pagina/ dados-cientificos-do-projeto-financiado?ident=280-2007 > . Acesso em: 3 jul. 2013.

WILLIAMS, R. Cultura e materialismo. Tradução de André Glaser. São Paulo: Editora da UNESP, 2011.

Submetido em 4 de julho de 2013.

Aprovado em 25 de julho de 2013. 